\title{
PROFISSÃO DESIGNER: A ATIVIDADE PROFISSIONAL SOB A ÓTICA DE BLOGS BRASILEIROS DE DESIGN
}

\author{
Isabela de Mattos Ferreira \\ Doutoranda em Design pela PUC-Rio \\ belawang@gmail.com \\ Vera Lúcia Nojima, Drạ \\ PUC-Rio \\ nojima@puc-rio.br
}

\begin{abstract}
Resumo: O designer, no exercício profissional, encontra dificuldades para o delineamento conceitual do campo de atividade. Tal circunstância vem sinalizar uma carência de identidade profissional do Design, inclusive quando comparado a outras profissões que possuem conceitos e definições bem fundamentados e reconhecimento comprovado pela sociedade. Em blogs ${ }^{1}$ brasileiros sobre Design, foram analisadas informações e opiniões dos designers internautas sobre a profissão. A quantidade e variedade de comentários dos pequenos textos coletados possibilitaram uma análise de conteúdo que serviu para a formulação das questões para questionários que foram aplicados aos proprietários dos blogs pesquisados. Intenciona-se com o presente trabalho intensificar as discussões sobre o reconhecimento da profissão.
\end{abstract}

Palavras-chave: Designer, Transversalidade, Interdisciplinaridade, Profissão, Identidade.

\begin{abstract}
The designer in his professional practice finds it difficult to design the conceptual field of activity. This circumstance indicates a fragile professional identity when compared to other professions that have established concepts and definitions that the society recognizes. An analysis was made about the designers' opinions about their profession on Brazilian Design Blogs ${ }^{2}$. The quantity and variety of information was
\end{abstract}

\footnotetext{
${ }^{1}$ Blog - Em um site Web, um blog, abreviação de arquivo na Web ou weblog, é um diário pessoal frequentemente atualizado e direcionado ao consumo do público em geral. Os blogs geralmente representam a personalidade do autor ou do site Web e seu objetivo. Às vezes, os tópicos incluem breves devaneios filosóficos, comentários sobre a internet e outras questões sociais e se liga a outros sites que o autor favoreça. As características essenciais do blog são seu formato de diário, normalmente um novo registro a cada dia, e seu estilo informal (THING, 2003, p.99).

${ }^{2}$ Blog - Short for Web log, a blog is a Web page that serves as a publicly accessible personal journal for an individual. Typically updated daily, blogs often reflect the personality of the author or the objective of a website. Sometimes, the topics includes short philosophical thoughts, comments about the web and social issues. It hás links for other blogs choosen by the author. The main caracteristics about a blog is
} 
important for the formulation of a questionnaire to the owners of those design blogs. The intention of the present work is to intensify the discussion about design profession recognition.

Keywords: Designer, Transversality, Interdisciplinarity, Profession, Identity.

\section{INTRODUÇÃO}

O objetivo do trabalho foi verificar como o profissional designer é percebido, qualificado e classificado pela sociedade e pelo mercado, considerando, sobretudo, seu reconhecimento. Além disso, pretende-se estimular os debates em torno da questão do reconhecimento profissional. O Design é uma atividade profissional pouco reconhecida na sociedade e pelo mercado. O emprego indiscriminado do termo "design" oportuniza que sejam atribuídas a ele diferentes e variadas acepções, como arte, bela forma, projeto, técnica, etc. e, por outro lado, que sirvam inclusive de referência a muitos setores da sociedade, como marketing, institutos de beleza, comércio e prestação de serviços.

A definição formulada por Axel Honneth (2003) de que a construção da identidade é um processo intersubjetivo de reconhecimento mútuo permite afirmar que a construção da identidade profissional deve ser entendida como processual e constituída por representações individuais e coletivas, numa relação de complementaridade entre essas dimensões dentro do contexto histórico. Portanto, a não equiparação da atividade profissional do designer com as demais profissões em vigor dificulta a consolidação da identidade do Design, visto que ainda se encontra na categoria de ocupação. Tanto que, no contexto brasileiro, qualquer pessoa pode se dizer designer, uma vez que a atividade profissional é apenas uma ocupação, uma atividade banalizada.

\section{METODOLOGIA}

Inicialmente, obteve-se, em blogs brasileiros sobre Design, informações e opiniões dos designers internautas sobre a profissão, a partir de textos em que discutem a atividade profissional. A quantidade e variedade de comentários dos pequenos textos coletados possibilitaram uma análise de conteúdo que, mesmo incipiente, ofereceram material para a formulação das questões para questionários que foram aplicados via internet (e-mail) aos proprietários dos blogs pesquisados. Em entrevistas não diretivas, foi utilizado como instrumento de coleta de opinião um roteiro semiestruturado composto por cinco perguntas abertas para profissionais liberais, professores e proprietários de grandes escritórios de Design. Para manter a homogeneidade, o corpus da pesquisa foi delineado, obedecendo ao foco temático, a partir dos seguintes assuntos: a relevância da regulamentação para a valorização da profissão, as questões de autoria e a importância da ideologia na profissão. Pretendeuse compreender o que os designers pensam a respeito de sua profissão, como eles imaginam que a sociedade os vê e descobrir a posição dos designers com relação à regulamentação.

the daily or almost daily update and an informal style (Traduced to English by the author. Extracted from THING, 2003, p. 99). 


\section{DESENVOLVIMENTO}

Doze blogs brasileiros de Design foram escolhidos, por conterem textos referentes à visão da sociedade e do mercado sobre a atividade profissional do designer. São eles:

Blog Ligia Fascioni - de Lígia Fascioni uma engenharia elétrica, que, depois de onze anos de profissão, começou a se especializar em Design e em Marketing assuntos aprestados no blog.

Blog Designers Justiceiros - formado por cinco designers Guilherme Xavier, Daniel Pinna, Ricardo Artur Carvalho, Daniel Borges e Gabriel Cruz, que, inconformados com a banalização da profissão e com os trabalhos de qualidade duvidosa realizados por "micreiros", resolveram criar um blog para denunciar e ironizar esses trabalhos e a visão que a sociedade tem dos designers.

IFD blog - de Íris Freitas Duarte, publicitária de formação que, ao longo de sua experiência profissional, entrou em contato e se encantou pelo universo do Design.

Filosofia do Design - de Marcos Beccari, designer de formação que tem trabalhos em que relaciona o Design com a Filosofia.

Design Simples - blog, que recebe o mesmo nome do escritório de Design de Rafael Gatti, conta com um variado número de colaboradores e disponilibiza matérias sobre as diversas especializações do Design.

Design.nerd, Designflakes, Chocoladesign, Caligrafitti, Design.blog, Needesign e Ser designer é - são blogs com atualidades sobre o campo do Design, bem como um espaço para divulgação de Portfólios.

Dos textos desses blogs, três foram selecionados sob o critério de que fossem representativos e que apresentassem comentários mais relativos ao tema.

O primeiro texto, do Blog Ligia Fascioni de 22 de setembro de 2010, discorre sobre um anúncio publicitário de uma escola de inglês, onde está estampado o texto:

'SE VOCÊ É ESTUDANTE E SONHA VIRAR DESIGN (sic), MANDE SEU CURRÍCULO E PORTFÓLIO PARA YEABABY.COM.BR. NOVE MESES PARA O ESTUDANTE VIRAR GENTE NO MERCADO'

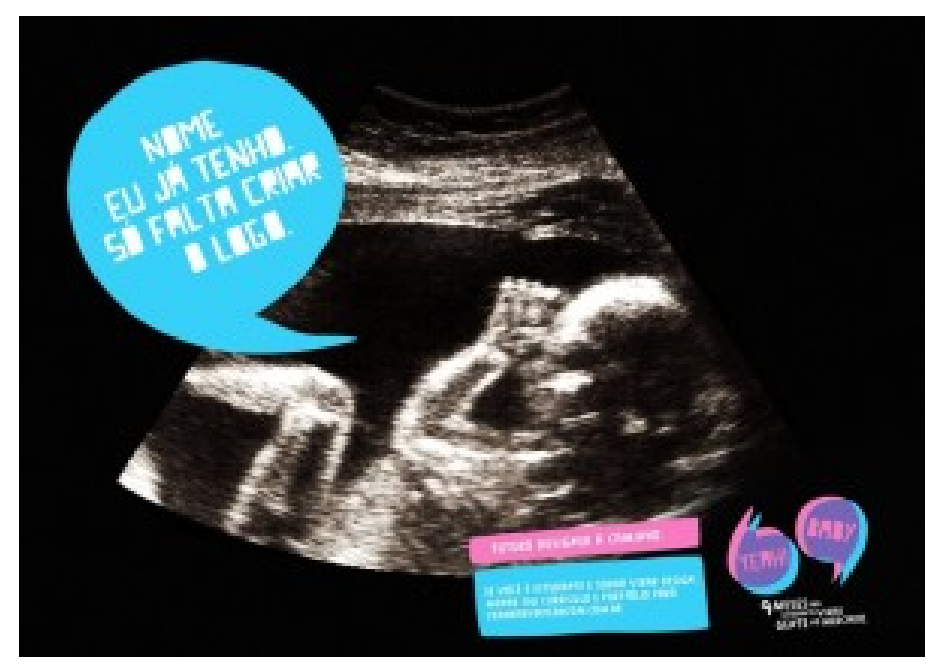

Figura 1 - Cartaz extraído do blog Ligia Fascioni 


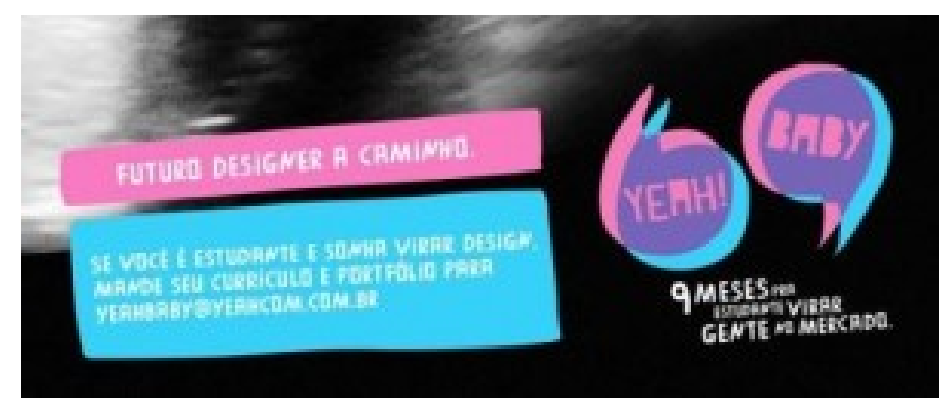

Figura 2 - Detalhe do cartaz extraído do blog Ligia Fascioni

A blogueira ${ }^{3}$ fez uma crítica ácida ao anúncio, pois quem desenvolveu a peça publicitária não sabe a diferença entre as palavras design (atividade profissional) e designer (o profissional) e faz uso das expressões 'virar design' e 'virar gente no mercado', como se somente a experiência profissional fizesse o estudante se tornar um designer.

Este anúncio motivou muitos comentários e claras demonstrações de insatisfação de designers, como: “Depois disso e de um site de um 'design-publicitário' com graduação em micreiragem que eu acabei de ver, minha manhã de sexta foi pro espaço. Quanta desvalorização existe na profissão pela própria profissão", ou "sem falar nessa coisa de "virar design" - como assim, Bial? Dá uma reboladinha e... virou? Pelo jeito, o pileque dos criativos foi tão grande que acharam a ideia genial a ponto de reaproveitá-la na outra frase onde eles prometem que os estudantes vão virar gente!" e "queria entender a cabeça do "design" que fez isso. Ele deve ficar feliz de tratar a própria profissão com tanto descaso".

Outro texto selecionado foi do blog Designers Justiceiros de 10 de abril de 2010. É a reprodução de um e-mail que um dos autores do blog recebeu contendo uma lista das "50 razões para não casar com um designer".

No texto os blogueiros criticaram uma lista intitulada "50 razões para não casar com um designer gráfico", publicada em outro blog, espaço.com. A lista apresenta uma visão caricata e negativa dos profissionais e da imagem que a sociedade tem sobre o designer. Os blogueiros discordaram de boa parte da lista e afirmam que há uma confusão com outras profissões como o marketing ou a fotografia.

A discussão foi aberta para os internautas se manifestarem. Entre os comentários, por exemplo, surgiram críticas à inclusão do termo 'job'. Segundo alguns internautas esse termo veio da publicidade e por esse motivo não deveria ser utilizado por designers, além de ser um estrangeirismo exacerbado. Outros afirmaram que esse termo deva ser utilizado, pois boa parte do mercado usa e o profissional designer poderia utilizar termos de outras áreas do conhecimento por ser uma profissão que trabalha interdisciplinarmente em conjunto com outras profissões.

O terceiro e último texto selecionado foi "Ser designer gráfico ou ganhar a vida de outro jeito?", do IFD blog, publicado em 04 de janeiro de 2010, cuja fonte foi

\footnotetext{
${ }^{3}$ Blogueira ou blogueiro é o termo feminino e masculino informal que designa uma pessoa que é dono de um blog e que fica conhecida pelo conteúdo que disponibiliza em seu site pessoal.
} 
a revista online Webinsider ${ }^{4}$. No texto, a autora questiona se a profissão de designer gráfico que, segundo ela é uma profissão em que geralmente se ganha pouco, deve ser exercida ou se deve escolher uma profissão que dê alguma estabilidade.

A conclusão da autora é otimista de que no momento a profissão não ganha bem, mas que em todas as profissões existem ciclos e pode ser que haja futuramente um ciclo de valorização da profissão e de aumento de salário, foi foco de da maioria dos comentários, como:

Não existe paixão ou amor pela profissão que resista uma boa enxurrada de boletos e contas chegando todos os meses. Profissões pragmáticas do tipo "advogado, engenheiro, arquiteto, jornalista, etc) são bem melhores".

ou

A profissão de designer gráfico é extremamente nova, um filhote ou primo pobre dos designers que viviam dentro das agências de publicidade e que resolveram dar um nome e formato a isso. portanto, ser publicitário é bem melhor do que ser designer.

ou

Saiam disso o mais rápido possível, vão ser arquitetos (é possível utilizar um monte de criatividade nessa área), qualquer coisa, menos...designer. é com profundo pesar digo estas palavras, mas o fato é que o mercado nunca se valorizou. $O$ que...quando é que se falou sobre um booom na profissão?

$\mathrm{e}$

Esta história de "fazer o que gosta" x "dinheiro" é uma discussão interminável, pra mim a partir do momento que você faz o que gosta e o faz bem, ganhar dinheiro é inevitável é uma consequência, principalmente quando vc tem contatos na área, e sabemos que na área de design como de publicidade ter contato e lógico ser bastante profissional e experiente conta muito para o quesito "salário/dinheiro".

A partir dos textos e dos respectivos comentários foram levantados os termos/ palavras/frases, cuja frequência possibilitou criar duas categorias, dentro de uma relação semântica relacionada ao campo do Design, sobre as quais se chegou a algumas reflexões.

\begin{tabular}{|l|l|l|}
\hline CATEGORIAS & ASPECTOS POSITIVOS & ASPECTOS NEGATIVOS \\
\hline Design & $\begin{array}{l}\text { criação } \\
\text { inovação } \\
\text { projeto }\end{array}$ & $\begin{array}{l}\text { banalização } \\
\text { não regulamentação } \\
\text { futilidade } \\
\text { desvalorização }\end{array}$ \\
\hline A profissão de designer & $\begin{array}{l}\text { talento } \\
\text { freelance } \\
\text { profissionalização } \\
\text { paixão }\end{array}$ & $\begin{array}{l}\text { falta de direitos } \\
\text { baixa remuneração } \\
\text { desvalorização } \\
\text { descaso } \\
\text { insatisfação } \\
\text { falta de estabilidade }\end{array}$ \\
\hline
\end{tabular}

Quadro 1 - Categorias resultantes da análise dos discursos dos blogueiros

\footnotetext{
${ }^{4}$ Webinsider é uma publicação da Z Editores Ltda., um site de artigos e conteúdo analítico sobre marketing, negócios, criação e conteúdo no ambiente online. Disponível em <http://webinsider.uol.com.br/2006/01/05/revistas-no-formato-revista/>. Acesso em 2 de agosto de 2011.
} 
Depreende-se dessa classificação que o Design é quase sempre entendido como uma área relacionada à criação e à inovação e que tem como características o desenvolvimento de projetos. Por outro lado, encontra-se com muita frequência a noção de que design não é só uma atividade que lida com futilidades, mas se trata de qualidade(s) que caracterizam qualquer produto, banalizando e desvalorizando a profissão e os profissionais, não recompensados de maneira proporcional ao investimento despendido na formação e especialização. Outros aspectos que dificultam a valorização são a falta de regulamentação da profissão, baixa remuneração, ausência de direitos, etc. o que se reflete na insatisfação dos profissionais que participaram dos blogs.

As reflexões sobre os resultados da análise dos blogs apontaram para questões cruciais no entendimento negativo da identidade conferida ao Design e ao designer. $O$ que realmente constitui a natureza da profissão? A regulamentação se mostra importante na valorização da profissão? A questão da autoria é importante para essa valorização? Existe um design brasileiro que o distingue dos demais e que, de certa forma, possa exercer influência na construção da identidade da profissão?

\section{Dos questionários}

Quatro perguntas compuseram o questionário enviado por meio digital para 25 pessoas envolvidas com os blogs visitados:

1. Como se configura a identidade do Design brasileiro?

2. O Design é uma atividade de natureza artística, estética, científica ou social? Acredita que algum aspecto se sobressaia ao outro?

3. Por que a questão da autoria é importante em um projeto de Design?

4. Quais as vantagens de uma possível regulamentação da atividade profissional do designer?

Nove questionários foram respondidos pelos seguintes blogueiros ${ }^{5}$ :

Beto Lima do Needesign é designer, dono e diretor criativo do Beto Lima Design e professor nas Faculdades Integradas Hélio Alonso e Faculdades Integradas Rio Branco. Daniel Pinna, do blog Designers Justiceiros é mestre em Design pela PUC-Rio e professor da UFF no Departamento de Cinema com especialização em Animação. Guilherme Xavier, do blog Designers Justiceiros, doutorando em Design pela PUC-Rio, professor dessa instituição é prorpietário do Dinergia, escritório especializado em design de jogos. Ricardo Artur Carvalho, do blog Designers Justiceiros é doutor em Design pela PUC-Rio, professor nessa instituição e na faculdade de Design Infnet. Íris Freitas Duarte, do IFD Blog; Lígia Fascioni, do blog com o mesmo nome. Marcos Beccari do Filosofia do Design é doutorando em educação na USP, mestre em Design e designer gráfico pela UFPR. Maria Renata Morales do Design Flakes é pós-graduada pelo SENAC e graduada em Design e Marketing pela Universidade de Mogi das Cruzes. Uno de Oliveira do Caligrafitti é graduado em Design e Marketing pela ESPM.

\footnotetext{
${ }^{5}$ Blogueiro(a) é o termo informal que utilizado na internet para designar o proprietário de um blog.
} 


\section{Como se configura a identidade do design brasileiro?}

Para Beto Lima, o Design brasileiro, de forma alguma, é inferior ao Design de países mais desenvolvidos e que se pode encontrar designers brasileiros trabalhando em qualquer parte do mundo com certa frequência. Destaca, portanto, a qualidade dos profissionais brasileiros de design.

Daniel Pinna acredita que, para uma identidade do Design brasileiro, é preciso estabelecer padrões. Comenta também que a antropofagia, sendo uma característica da identidade do brasileiro é, consequentemente, do Design brasileiro. Além disso, salienta a importância do multiculturalismo.

Guilherme Xavier faz menção à importação de modelos europeus, mesclada

com uma cultura de problemáticas e solucionáticas [sic] locais. O que caracteriza a identidade do design nacional é justamente sua multitudes [sic] de facetas de uso e expertises, que variam do vernacular ao acadêmico. Da total heurística e experimentação ao erudito nomatizado.

Ricardo Artur Carvalho crê que a pós-modernidade trouxe uma fragmentação das identidades em decorrência da globalização. Para ele, a emergência de outras muitas identidades, como étnicas, sociais, locais, "tem contribuído para uma mudança significativa sobre o entendimento do que é uma identidade nacional. Em especial no Brasil, um país que se caracteriza pelas misturas culturais, fica difícil precisar algo único que possa ser chamado de brasileiro". Coloca que, talvez, o Design brasileiro se caracterize pela falta de unidade, pela diversidade, pela multiplicidade de manifestações.

Íris Freitas indigna-se com a falta de reconhecimento da profissão pelo mercado, pois "num país que confeiteiro vira designer de bolo, às vezes, de verdade, chega a frustrar algumas coisas que vejo por aí, creio eu que a regulamentação elevaria o design a ser realmente levado a sério aqui pelas bandas tupiniquins". Por outro lado, comunga da opinião de Beto Lima. Também comenta que

o Brasil é reconhecido muito por esta área, acho engraçado isso, num país onde nem o designer tem seu devido valor, dúzias de meninos se vendem em fóruns vendendo seu trabalho por pouco, lá fora o design brasileiro é visto com outro nível, mas a realidade aqui principalmente para o profissional é outra.

Ligia Fascioni diz não ter uma resposta para esta questão. Comenta sobre o multiculturalismo. Fala da preocupação com a sustentabilidade e a criatividade, mas essas características existem no Design como um todo, está no mundo inteiro.

Marcos Beccari acredita que, embora o Design traga um mundo imaginário tão imprevisível quanto sedutor, no Brasil ainda não assumiu totalmente esse papel. Está aos poucos abandonando a questão da forma e função e descobrindo a sensibilidade e a sedução para se relacionar com as pessoas que consomem design.

Maria Renata Morales entende que a identidade do Design brasileiro ainda está se moldando, não tem uma configuração bem definida, já que é muito influenciado pelo que vem de fora e comenta que alguns designers conseguem se sobressair por imprimirem em seus trabalhos uma certa irreverência.

Uno de Oliveira entende que o Brasil passa por uma fase importante em sua história, consequência de um crescimento que vem acontecendo há décadas atrás e 
que traz hoje a esperança de sermos a potência que os governos anteriores tinham como meta. E isso reflete em todas as profissões. "O aumento do estudo e conhecimento sobre a área nos dá mais embasamento para opiniões, criações e uma ótima execução do trabalho. A identidade pra mim é essa, uma efervescência de criação totalmente de acordo com os estilos gráficos utilizados hoje".

\section{O Design é uma atividade de natureza artística, estética, científica ou social? Acredita que algum aspecto se sobressaia ao outro?}

Beto Lima respondeu que a atividade do Design é baseada numa necessidade e que depois se desenvolve um conceito e por fim um projeto, que pode ter caráter social e /ou empresarial.

Daniel Pinna assegurou que o Design é uma atividade técnica, é uma atividade criativa, porém não artística, mas que tem um caráter estético e social muito importante. Ademais, existe uma questão primordial, que é a da funcionalidade, que acaba perpassando tanto o uso, como a fabricação, a estética, a sedução do produto, o valor social dos objetos e o científico. Porém, para ele, o mais relevante na natureza do Design seria a questão do método. A metodologia se relaciona com a técnica e a prática.

Guilherme Xavier asseverou que "não há sobressaliência [sic] hierárquica, somente entendimento de objetivo, causa e efeito" nos projetos de Design. Porém, antes de ser uma atividade artística, estética, científica ou social é uma atividade intelectual. "Design existe primeiro na mente e só depois é posto em prática. Antes de se mostrar como atividade, design é um pensamento. Design tem natureza filosófica, portanto".

Ricardo Artur Carvalho entende que além das diferentes correntes ideológicas e filosóficas das instituições, existem as práticas de certos setores do Design. Exemplifica com a atividade de projetar carros, em que os aspectos ergonômicos e mecânicos são os mais importantes, que se contrapõem ao Design de cartazes, que possui uma aproximação maior com as artes plásticas. E foi assertivo, ao dizer que a natureza do campo é múltipla e se adequa de acordo com a ocasião e o ponto de vista de quem pratica.

Íris Freitas Duarte entende o Design envolve todos esses aspectos, inclusive para ser considerado um design de qualidade, um "bom design".

Ligia Fascioni respondeu que

o design reúne elementos artísticos, estéticos e científicos para fazer uma contribuição social. Design é, e continua cada vez mais, se projetando como uma atividade social ele vem mudando a vida das pessoas ao longo do tempo e sua influência é cada vez mais flagrante em tempos de preocupação com a sustentabilidade e consumidores mais exigentes.

Para Marcos Beccari, o social é o aspecto que mais se sobressai na atuação em Design. No entanto, estes conflitos (design é arte? estética? ciência, etc.), segundo ele, envolvem questões difíceis (ideologia, paradigmas históricos, ontologia, política, etc.) e que "não se resolvem neste ou naquele posicionamento, mas que revelam novas formas de ver o mundo enquanto pensamos sobre elas. Acredito que, ao mantermos vivos estes conflitos (sem resolvê-los), estamos criando realidades". Beccari vê como principal questão para o campo, a importância das "trocas simbólicas", pelas quais as 
pessoas se comunicam através de objetos e imagens e nos discursos que as definem enquanto sujeitos (valores, princípios, ideologias). Assegura que os discursos ideológicos estão inseridos nestas trocas, prontos para serem negociados.

Maria Renata vê a atividade como científica, estética e projetual. Afirma que o aspecto estético é usado para seduzir o consumidor, só que o que diferencia a atividade de um designer do de um micreiros é a forte estruturação científica que existe por detrás do apelo estético.

Uno de Oliveira acha que esses aspectos têm pesos equilibrados. "A natureza artística aliada à função pode ser uma das explicações para a pergunta. O que é o Design?" E uma cidade ou produtos com uma qualidade gráfica melhor, uma informação que passe exatamente seu significado, têm por função: agradar, vender e seduzir quem os observa, esta é, para ele, uma função social do design.

\section{Por que a questão da autoria é importante em um projeto de Design?}

Beto Lima responde que existe cópia, sim, pois todos querem ser pais de "filhos bonitos".

Daniel Pinna disse que não vê importância nesta questão e que geralmente os "grandes designers" acabam se sobressaindo na história a posteriori, ou seja, o próprio designer não aproveita da fama. Daniel avalia, colocando que, na verdade, o bom projeto de Design é aquele em que o designer vai estudar o problema, localizar a onde está a lacuna e, a partir daí, vai buscar as soluções. A imposição de um estilo sobre as soluções tende a fazer com que a função não seja tão eficaz.

Guilherme Xavier disse acreditar na importância da autoria, pois assim se determina uma memória da produção e aponta responsabilidades legais, sociais, econômicas e éticas e que crê ser "relevante que se saiba quais são os sujeitos e predicados dos processos, mesmo que não exista apenas um autor e sim grupos de criação".

Ricardo Artur Carvalho vê a autoria como um conceito concebido e valorizado na Era Moderna com o intuito de exaltar determinados indivíduos e destacá-los de outros, implicando valores de ordem simbólica e econômica. E diz que

muitas coisas são apropriadas, reapropriadas, alteradas e consumidas em uma velocidade muito alta. Se isso por um lado lesa uma enorme indústria que se baseia no monopólio de bens imateriais, por outro lado permite a circulação cada vez maior desses bens que são, essencialmente, ideias.

E assegura que tal movimento pode favorecer o surgimento de inovações científicas, econômicas, sociais e artísticas e de uma nova maneira do que estamos acostumados.

Íris Freitas Duarte afirmou que qualquer trabalhador de qualquer área quer ser reconhecido pelo seu trabalho e que ter a criação usurpada por outra pessoa "sinceramente é um soco no estomago, pra maioria dos profissionais o reconhecimento através do trabalho vale muito mais do que o valor pago por ele".

Ligia Fascioni argumentou que a autoria serve para remunerar o investimento feito em pesquisa e possibilitar esta tenha continuidade. Comentou que a cocriação é cada vez mais presente e que isso dificulta na definição do que seja autoria, pois é difícil identificar quem é o autor, se é "quem teve a ideia, quem a viabilizou, quem fez a produção, quem fez o teste e contribuiu com sugestões na avaliação, o cliente, o 
usuário, ou o curioso que estava passando e deu uma ideia boa?". Um designer não faz mais um projeto sozinho e precisa da participação de muita gente, incluindo o próprio cliente. Maria Renata comunga do argumento de Ligia.

Marcos Beccari disse que nos processos criativos, a autoria para ele tem alguma relevância, mas que os designers não têm total liberdade de criação em um projeto de Design, por apenas articular um sentido dentro de fatores inevitáveis (briefing, orçamento, pré-requisitos, etc.). “O designer deve ser capaz de articular essa aparente ausência de liberdade no seio de seu processo criativo, de modo que um efeito compensador, jogando a seu favor, resulte em um sentido intencional e simultaneamente inevitável", o que faz parte de um discurso autoral. Para ele, portanto, "assim como uma cultura, uma ideologia ou um conjunto de normas éticosociais, um projeto de Design, em maior ou menor grau, sempre constitui um discurso autoral que nos orienta a agir diante do inevitável".

Maria Renata Morales respondeu que o designer deve ser respeitado e valorizado enquanto autor e no Brasil essa valorização é importante para diferenciar o designer daqui em relação aos outros.

Para Uno de Oliveira, a criação é como se fosse um filho, é parte de você que está ali e a cópia fere essa relação. Disse estar ciente de que a cópia é uma prática comum, por falta de capacidade ou conhecimento de quem a faz, que é "mais fácil copiar do que estudar e desenvolver um novo".

\section{Quais as vantagens de uma possivel regulamentação da atividade profissional do designer?}

Beto Lima respondeu que a regulamentação ajuda o designer que trabalha em órgãos do governo, pois dará à atividade uma definição correta. Para os demais designers, talvez um pouco mais de reconhecimento por parte da sociedade.

Daniel Pinna afirmou que uma atividade de criação não necessita ser regulamentada. Têm profissões em que se precisa de um sindicato para cobrar uma segurança mínima para se trabalhar e outras que têm uma responsabilidade muito grande como a atividade do médico e a do advogado, mas não é o caso do design. Desconfia que sindicatos e associações realmente sejam bons para profissões relacionadas à criação, principalmente no Brasil, onde há muita burocracia. Existe uma questão de autoproteção e autopremiação das pessoas que têm cargos políticos dentro dessas associações e sindicatos. Além disso, quem tem anos de experiência, quem tem formação na área, já tem um mercado onde atua que não é afetado pelos micreiros, que cobram menos, mas que não tem o mesmo conhecimento. Ele crê que o mais importante é a defesa da identidade da profissão, da qualidade do serviço, da valorização e remuneração justa.

Guilherme Xavier falou que regulamentar é "definir limites e sendo a profissão do designer um ato de negociar o limiar entre áreas, seria um fardo legal excessivo que só viria a comprometer a pouca informação que a área ainda desfruta junto ao público". Disse entende que o Design é para todos, e a regulamentação, em molde exclusivista, dificultaria a participação do designer em outras áreas de conhecimento. Justificou que "ainda que o design pudesse ser feito só por designers, isso não impediria um pensamento de design que é livre e isento de qualquer censura, proibição ou regulagem". 
Ricardo Artur Carvalho disse entender que há mais desvantagens do que vantagens. Diz que há discursos sobre "reconhecimento social da profissão", "estabelecimento de pisos salariais" e "criação de sindicatos e agências de controle", mas, para ele, é algo bastante ultrapassado. Pensa que a reserva de mercado favorece pouco a profissão e promove o seu fechamento, que vai contra a natureza transversal do Design. Dificulta também o surgimento de novas áreas de atuação, como o design de serviços, por exemplo. Existe uma pequena vantagem de ordem política no sentido público. Comenta que há alunos que se diplomam com médias medíocres, enquanto há autodidatas e profissionais talhados pela própria prática e que possuem muita competência.

Íris Freitas Duarte disse que regulamentar a profissão teria como consequência a criação de um piso salarial, pois atualmente não existe uma tabela padrão. Além disso, a denominação designer não seria tão banalizada como é hoje em dia. Acha frustrante ver placas de designer de bolo, designer de sobrancelhas e hair designer e entende que a regulamentação diminuiria o uso incorreto da palavra.

Ligia Fascioni disse enxergar a regulamentação como uma forma antiga de garantir a atuação organizada de um profissional no mercado. E que, na prática, não funciona muito bem. Duvida que os clientes seriam bem-atendidos, pois o profissional pode fazer um trabalho ruim e não ser punido. Regulamentar para que os profissionais participem de concorrências é útil a um pequeno número de profissionais. Aponta como um aspecto positivo, a possível "homogeinização da formação básica do profissional, que é muito diferente e até conflitante nas diversas universidades e escolas do país". Concluiu, afirmando que a regulamentação dificilmente resolveria os problemas que existem hoje na profissão dos designers e que o mais importante é a organização da classe, independente dos meios oficiais.

Maria Renata respondeu que a regulamentação acabará com "classe micreira" e haverá precificação justa pelo trabalho do profissional qualificado.

Marcos Beccari disse não ver vantagens na regulamentação. Apesar de ser útil para incluir a profissão em editais de concursos públicos, entende que as pessoas têm o direito de fazer design sem ter que passar pela universidade. Percebe o design como uma atividade humana e que o estudo acadêmico em design deveria ser uma escolha, não um requisito.

Uno de Oliveira respondeu que a regulamentação ajudará na união e organização dos profissionais e a melhoraria da qualidade dos trabalhos.

\section{CONCLUSÃO}

A abordagem sobre identidade profissional, de um modo geral, implica na discussão a respeito da intersecção em que se situam, conforme Claude Dubar em $A$ socialização: construção das identidades sociais e profissionais (2005), o trabalho - o emprego - a formação. Ao longo da história social, vê-se que essa articulação se desarranja a despeito da valia e da pertinência conceitual da atividade ou da competência e empenho de quem a pratica, gerando instabilidade e ameaças à identidade profissional.

A demarcação dessa pertinência e valia esbarra na banalização do Design como consequência de sua própria natureza, fluida e multifacetada, caracterizada como multi e interdisciplinar, mediada por uma atitude transversal, marcando a amplitude de relacionamento que faz com diversas áreas do conhecimento. 
Se, por um lado, delimitar e classificar ou até regulamentar a profissão faz com que este caráter fundamental perca sua energia vital, por outro lado, a falta de clareza sobre o âmbito de limites e de foco do campo de atividade do Design representa obstáculos significativos para a carreira dos profissionais.

Os designers, recorrentemente, se queixam de que seu trabalho não é reconhecido. Ficam insatisfeitos com remuneração ou pró-labore que não compensam a constante atualização a que se submetem para vencer num mercado altamente competitivo e em franca mudança diante das inovações tecnológicas. O mapeamento e a discussão das ideias sobre os limites da prática profissional do designer no mercado de trabalho propostos na pesquisa em relato proporcionou a reflexão sobre algumas configurações conceituais da atividade profissional do Design.

A questão da autoria pode ser entendida como garantia dos direitos de quem realizou o projeto e/ou desenvolveu o produto ou apenas como uma tendência sob a influência do Marketing. Nesse caso, o designer ganha respeito e admiração tão grandes que tudo o que é a assinatura, transformada em grife sem levar em conta a viabilidade do projeto nem a qualidade de uso do produto.

Dessa forma, a construção da identidade do profissional do Design não pode como também não é desejável ser traçada linearmente, pois se trata de um empreendimento altamente complexo.

Vislumbra-se que a criação de um Conselho Profissional, que vise valorizar a profissão e resguardar os interesses sociais e contribuir para o aumento de sua força política, poderá auxiliar na melhoria da percepção da sociedade em relação à atividade profissional do design. É bom que fique claro que não se pretende aqui fazer apologia à reserva de mercado, mas sim fortalecer identidade profissional do Design, tão almejada pelos designers que responderam aos questionários.

A tentativa é de aproximar toda a discussão em torno da profissão designer de uma resposta para os motivos reais de reconhecimento da profissão. Acredita-se, assim, ter contribuído para o fomento da discussão dessa questão em aberto.

\section{REFERÊNCIAS}

ABEDESIGN - Associação Brasileira de Empresas de Design. Disponível em: < http://www.abedesign.org.br/2010/sobre.php>. Acesso em: 04 out. 2012.

Caligraffiti. Disponível em: <http://www.caligraffiti.com.br/>. Acesso em: 26 out. 2010.

Choco La Design. Disponível em: < http://chocoladesign.com/>. Acesso em: 26 out. 2010.

Classificação Brasileira de Ocupações: CBO - 2010 - 3a ed. Brasília : MTE, SPPE, 2010. v. 1828 p.

Design.Blog. Disponível em: <http://design.blog.br/>. Acesso em: 26 out. 2010.

Designers Justiceiros. Disponível em: <http://designersjusticeiros.blogspot.com/>. Acesso em: 26 out. 2010.

Design Flakes. Disponível em: <http://www.designflakes.com.br/>. Acesso em: 26 out. 2010. 
Design Simples. Disponível em: <http://www.designsimples.com.br/blog/>. Acesso em: 26 out. 2010.

DUBAR, Claude. A Socialização: A Construção das Identidades Sociais e Profissionais. São Paulo: Martins Fontes, 2005.

Filosofia do Design. Disponível em: <http://filosofiadodesign.wordpress.com/>. Acesso em: 26 out. 2010.

GERTEINY, Gilbert Gilles. Mundialização, Globalização, Localização e Glocalização. Disponível em: <http://ucam-poa.com.br/mundializacao-globalizacao-localizacao-eglocalizacao/>. Acesso em 3 de novembro de 2012.

HONNETH, Axel. Luta por reconhecimento: a gramática moral dos conflitos sociais. São Paulo: Ed. 34, 2003.

IFD blog. Disponível em: <http://www.ifd.com.br/blog/>. Acesso em: 26 out. 2010.

Lígia Fascioni. Disponível em: <http://ligiafascioni.com.br/blog/>. Acesso em: 26 out. 2010.

Needesign. Disponível em: <http://espaco.com/>. Acesso em: 26 out. 2010.

Site da ESDI - Escola Superior de Desenho Industrial. Disponível em: < http://www.esdi.uerj.br>. Acesso em: 04 out. 2012.

SANTOS, Maria Cecília Loschiavo dos. In: MORAES, DIJON. Cadernos de Estudo Avançado em Design, Caderno: Design e multiculturalismo. Belo Horizonte : Santa Clara : Centro de Estudos Teoria, Cultura e Pesquisa em Design. UEMG, 2008, v. 1, jul. 2008.

THING, Lowell. Dicionário de Tecnologia [tradução Bazán Tecnologia, Linguística e Texto Digital]. São Paulo: Futura, 2003.

WILENSKY, Harold L. The Professionalization of Everyone? American Journal of Sociology, v.70, n.2, sep., p.137-158, Chicago, The University of Chicago Press, 1964. 